\title{
Intermediate-to-therapeutic versus prophylactic anticoagulation for coagulopathy in hospitalized COVID-19 patients: a systemic review and meta- analysis
}

Sirui Zhang ${ }^{1+}$, Yupei Li2 ${ }^{2,3+}$, Guina Liu ${ }^{1}$ and Baihai Su',2,3,4,5*

\begin{abstract}
Background: Anticoagulation in hospitalized COVID-19 patients has been associated with survival benefit; however, the optimal anticoagulant strategy has not yet been defined. The objective of this meta-analysis was to investigate the effect of intermediate-to-therapeutic versus prophylactic anticoagulation for thromboprophylaxis on the primary outcome of in-hospital mortality and other patient-centered secondary outcomes in COVID-19 patients.

Methods: MEDLINE, EMBASE, and Cochrane databases were searched from inception to August 10th 2021. Cohort studies and randomized clinical trials that assessed the efficacy and safety of intermediate-to-therapeutic versus prophylactic anticoagulation in hospitalized COVID-19 patients were included. Baseline characteristics and relevant data of each study were extracted in a pre-designed standardized data-collection form. The primary outcome was all-cause in-hospital mortality and the secondary outcomes were incidence of thrombotic events and incidence of any bleeding and major bleeding. Pooled analysis with random effects models yielded relative risk with $95 \%$ Cls.
\end{abstract}

\footnotetext{
* Correspondence: subaihai@scu.edu.cn

†'Sirui Zhang and Yupei Li contributed equally to this work.

'West China School of Medicine, Sichuan University, 610041 Chengdu, China ${ }^{2}$ Department of Nephrology, Med+ Biomaterial Institute, West China Hospital, Sichuan University, 610041 Chengdu, China

Full list of author information is available at the end of the article
}

(c) The Author(s). 2021 Open Access This article is licensed under a Creative Commons Attribution 4.0 International License, which permits use, sharing, adaptation, distribution and reproduction in any medium or format, as long as you give appropriate credit to the original author(s) and the source, provide a link to the Creative Commons licence, and indicate if changes were made. The images or other third party material in this article are included in the article's Creative Commons licence, unless indicated otherwise in a credit line to the material. If material is not included in the article's Creative Commons licence and your intended use is not permitted by statutory regulation or exceeds the permitted use, you will need to obtain permission directly from the copyright holder. To view a copy of this licence, visit http://creativecommons.org/licenses/by/4.0/. The Creative Commons Public Domain Dedication waiver (http://creativecommons.org/publicdomain/zero/1.0/) applies to the data made available in this article, unless otherwise stated in a credit line to the data. 
Results: This meta-analysis included 42 studies with 28,055 in-hospital COVID-19 patients totally. Our pooled analysis demonstrated that intermediate-to-therapeutic anticoagulation was not associated with lower in-hospital mortality ( $\left.R R=1.12,95 \% \mathrm{Cl} 0.99-1.25, p=0.06, \mathrm{l}^{2}=77 \%\right)$ and lower incidence of thrombotic events ( $R R=1.30,95 \% \mathrm{Cl}$ $\left.0.79-2.15, p=0.30, I^{2}=88 \%\right)$, but increased the risk of any bleeding events $\left(R R=2.16,95 \% \mathrm{Cl} 1.79-2.60, p<0.01, I^{2}=31 \%\right)$ and major bleeding events significantly $\left(R R=2.10,95 \% \mathrm{Cl} 1.77-2.51, p<0.01, I^{2}=11 \%\right)$ versus prophylactic anticoagulation. Moreover, intermediate-to-therapeutic anticoagulation decreased the incidence of thrombotic events ( $R R=0.71,95 \% \mathrm{Cl} 0.56-0.89, \mathrm{p}=0.003, \mathrm{I}^{2}=0 \%$ ) among critically ill COVID-19 patients admitted to intensive care units (ICU), with increased bleeding risk ( $\left.R R=1.66,95 \% \mathrm{Cl} 1.37-2.00, p<0.01, \mathrm{I}^{2}=0 \%\right)$ and unchanged in-hospital mortality ( $R R=0.94,95 \% \mathrm{Cl} 0.79-1.10, \mathrm{p}=0.42, \mathrm{I}^{2}=30 \%$ ) in such patients. The Grading of Recommendation, Assessment, Development, and Evaluation certainty of evidence ranged from very low to moderate.

Conclusions: We recommend the use of prophylactic anticoagulation against intermediate-to-therapeutic anticoagulation among unselected hospitalized COVID-19 patients considering insignificant survival benefits but higher risk of bleeding in the escalated thromboprophylaxis strategy. For critically ill COVID-19 patients, the benefits of intermediate-to-therapeutic anticoagulation in reducing thrombotic events should be weighed cautiously because of its association with higher risk of bleeding.

Trial registration: The protocol was registered at PROSPERO on August 17th 2021 (CRD42021273780).

Keywords: COVID-19, Anticoagulation, Mortality, Bleeding, Thromboprophylaxis, Meta-analysis

\section{Background}

Coronavirus disease 2019 (COVID-19), provoked by severe acute respiratory syndrome coronavirus- 2 infection, is currently the most serious public health crisis worldwide [1]. Patients who are hospitalized with COVID-19 frequently have macrovascular and microvascular thrombosis and inflammation, which may contribute to high morbidity and mortality [2-7]. In a recent metaanalysis of 49 studies enrolling 18,093 hospitalized patients with COVID-19, the overall estimated pooled incidence of venous thromboembolism was $17.0 \%$, with a higher incidence $(27.9 \%)$ among those admitted to intensive care unit (ICU) [8]. Mechanisms of hypercoagulable state in these patients have not been fully elucidated yet, and may potentially attribute to immunothrombosis that is mediated by abnormal endothelial dysfunction and platelet activation [9-11]. Accordingly, several national and international clinical guidance reports have recommended the use of prophylactic anticoagulation in hospitalized COVID-19 patients who do not have a contraindication to anticoagulant administration for thromboprophylaxis [12-15].

However, increasing evidence demonstrated that some COVID-19 patients, especially those with critical illness, still developed severe thrombotic complications despite the use of prophylactic anticoagulant [16-18]. Enhanced-dose anticoagulation strategies have thus been recommended by some guidance statements in critically ill COVID-19 patients [19-21], though patients may also develop bleeding complications on elevated anticoagulation treatment. The effectiveness and safety of intermediate-to-therapeutic anticoagulation are still uncertain [22].
Previous meta-analyses that investigated the optimal anticoagulation strategy only included limited studies and reported inconsistent conclusions [23-25]. As more evidence from high-quality randomized controlled trials (RCTs) and observational cohort studies have become available recently, we conducted an updated metaanalysis to investigate the efficacy and safety of intermediate-to-therapeutic versus prophylactic anticoagulation in COVID-19 patients with subsequent subgroup analyzes being performed in critically ill COVID19 patients further.

\section{Methods}

This review was conducted following the Preferred Reporting Items for Systemic Reviews and MetaAnalyses (PRISMA) Statement [26] and registered on the Open PROSPERO Framework (registration number: CRD42021273780).

\section{Search strategy}

Literature search was conducted strictly and comprehensively in MEDLINE, EMBASE, and Cochrane databases. Two independent investigators (ZSR and LYP) searched studies available from database inception to August 10th 2021 without language limitation. The following key words and/or medical subject heading terms were used: 'COVID', 'COVID-19', '2019 novel coronavirus infection', 'SARS-CoV-2', '2019-nCoV disease', 'anticoagulation', 'anticoagulants', 'anticoagulant', 'unfractionated heparin', 'UFH', 'fondaparinux', 'enoxaparin', 'low-molecular-weight heparin', 'LMWH', 'heparin, low molecular weight', 'heparin', 'antithrombotic', and 'anti- 
thrombosis', 'thromboprophylaxis' [see Additional file 1 for the detailed search strategy].

\section{Study selection}

Two independent investigators (ZSR and LYP) performed the initial screening of titles and abstracts. Fulllength articles of identified studies were retrieved to assess eligibility. Any discrepancies were adjudicated by a third reviewer $(\mathrm{SBH})$. The inclusion criteria of our metaanalysis were as follows: (1) cohort studies and RCTs, (2) studies that enrolled COVID-19 patients admitted to general wards or ICUs, and (3) studies that compared the efficacy or safety of intermediate-to-therapeutic versus prophylactic anticoagulation. The exclusion criteria were as follows: (1) studies enrolling out-hospital COVID-19 patients, or (2) animal experiments, case reports, reviews, comments, editorial comments, or (3) no relevant and sufficient data on preferred outcomes. In case a same patient population was enrolled in a few articles, we only selected the most comprehensive study.

\section{Data extraction}

After study selection, the following data were extracted: author, publication year, study type, study location, patient characteristics, numbers of patients in different groups, in-hospital mortality, incidence of any bleeding events, incidence of major bleeding events, and incidence of thrombotic events using a predesigned standardized data-collection form by two researchers (ZSR and LYP) independently.

\section{Quality assessment}

Quality assessment of studies were conducted by two independent reviewers (ZSR and LYP). The Cochrane Collaboration tool was used to assess the risk of bias in randomized controlled trials [27]. The quality of cohort studies was assessed using the Newcastle-Ottawa Scale (NOS) [28], evaluating three aspects: (1) selection of study groups, (2) comparability of study groups, and (3) outcome ascertainment. Meanwhile, we rated the quality of evidence for each outcome in the pooled analysis as high, moderate, low, and very low quality by the Grading of Recommendations Assessment, Development and Evaluation (GRADE) framework [29].

\section{Study outcomes}

Our primary outcome was all-cause mortality during hospitalization for COVID-19. Secondary patientcentered outcomes included the incidence of bleeding events and thrombotic complications during hospitalization for COVID-19. We also investigated these outcomes in critically ill COVID-19 patients who were admitted to ICU exclusively. Definitions of bleeding events depended on the variable definitions of each study, mostly in accordance with Myocardial Infarction (TIMI) bleeding [30] or the World health organization bleeding scale [31, 32]. Major bleeding was mostly defined by the criteria of the International Society on Thrombosis and Haemostasis (ISTH) [33]. Thrombotic complications mainly included deep venous thrombosis and pulmonary embolism, or jointly venous thromboembolism.

\section{Statistical analysis}

Risk ratios (RR) with $95 \%$ confidence interval (CI) were calculated for dichotomous outcomes such as mortality, bleeding events and thrombotic complications. A random effects model was applied for meta-analyses due to the heterogeneity of study populations and design. Heterogeneity among studies was assessed by the chi-square test and shown as an $\mathrm{I}^{2}$ index (25-50\%: low heterogeneity; 50-75\%: moderate heterogeneity; greater than $75 \%$ : high heterogeneity). Sensitivity analysis was conducted by omitting each study at a time to determine whether each study affected the overall estimate and to identify studies that potentially drove the results. Publication bias was assessed with funnel plots and Egger test. A two-side P-value $<0.05$ was considered to be of statistical significance. All statistical analyses were carried out using the meta package in R 3.6.2 and Review Manager software (version 5.4).

\section{Results}

\section{Study Selection}

From 6,002 yielded studies, we retained 74 studies after removing duplications and screening titles and abstracts. Forty-two studies involving 28,055 subjects met the inclusion criteria and were finally included in this metaanalysis after full-text review. The PRISMA flow diagram demonstrates the process of study screening and selection in detail, as shown in Fig. 1.

\section{Study Characteristics}

Of the forty-two included studies, 6 studies [34-39] were RCTs and 36 studies [40-75] were cohort studies. Thirteen studies [34, 38, 39, 41, 43, 52, 55, 58, 61, 64, 67, 69, 70] were performed exclusively in patients admitted to ICU. Eighteen studies [34, 40, 42, 48, 51, 53-55, 57, 62-66, 68-70, 73] reported results from the United States and two $[37,38]$ were international studies. Other studies originated from eleven countries ( Italy $[47,49,56,58,60,72,75]$, France [41, 61, 67], Brazil [35, 36], England [59], Greek [46], China [45], Japan [43], Mexico [44], United Arab Emirates [52, 71], Turkey [74], Iran [39] and Spain [50] ).

We included a pooled population of 23,579 hospitalized COVID-19 patients [34-49, 51-61, 63-68, 70-75] with reported information related to in-hospital mortality, 
Identification of studies via databases and registers

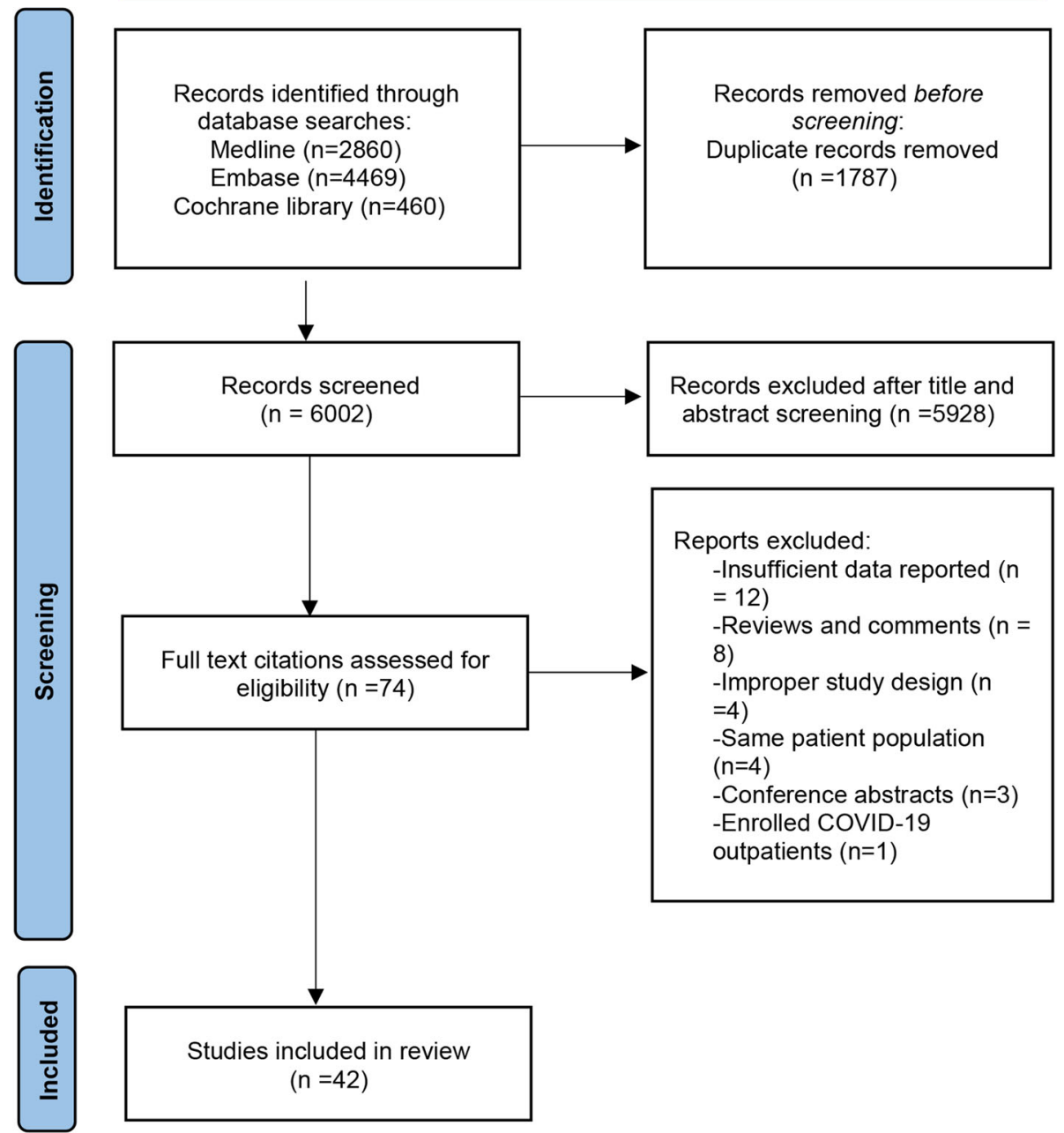

Fig. 1 Flowchart of selection of studies

19,275 patients $[34-41,44,46-48,50,51,53,55,58,59$, $61,62,64-67,70,71,73]$ with reported information related to bleeding events and 8492 patients [34-39, 41-43, $47,56,58,60-62,64,66]$ with reported information related to thrombotic events. The mean age in most studies was over 60 years. The proportion of male subjects ranged from 38.1 to $82.2 \%$. The types of administered anticoagulants, exact anticoagulation dosages and anticoagulation treatment duration varied widely across studies. Enoxaparin and unfractionated heparin were the most used anticoagulants in the included studies. Additional file 2 further summarized the detailed baseline characteristics of each study and the details of anticoagulation administration in each study were listed in Additional file 3.

\section{Assessment of study quality}

The score by NOS for the included cohort studies ranged from 6 to 9 , while 10 studies were of high quality scoring 9. A full assessment is shown in Additional file 4. Cochrane Collaboration Risk of Bias assessing bias of RCTs indicated low bias in the majority of included RCTs (Additional file 5).

\section{In-hospital mortality}

Data regarding in-hospital mortality of COVID-19 patients receiving prophylactic anticoagulation or intermediate-to-therapeutic anticoagulation were available from 39 studies [34-49, 51-61, 63-68, 70-75] (23,579 patients) which included both ICU and non-ICU patients. In-hospital mortality ranged widely across studies with an average of $22.1 \%$ for prophylactic anticoagulation group and $22.6 \%$ for intermediate-to-therapeutic anticoagulation group in non-ICU patients, while the average incidence of in-hospital death was $31.7 \%$ in prophylactic anticoagulation group and $31.1 \%$ in intermediate-to-therapeutic anticoagulation group in ICU patients. Figure 2a 


\begin{tabular}{|c|c|c|c|c|c|c|c|c|c|c|c|}
\hline \multirow{43}{*}{ a } & Study or Subgroup & \multicolumn{2}{|c|}{ I-TAC } & \multicolumn{2}{|c|}{$\begin{array}{l}\text { PAC } \\
\text { Events Total }\end{array}$} & Weight & $\begin{array}{c}\text { Risk Ratio } \\
\text { M-H, Random, } 95 \% \mathrm{Cl}\end{array}$ & \multicolumn{3}{|c|}{$\begin{array}{c}\text { Risk Ratio } \\
\text { M-H, Random, } 95 \% \mathrm{Cl}\end{array}$} & \\
\hline & Bikedeli 2021 & 127 & 276 & 123 & 286 & $4.2 \%$ & $1.07[0.89,1.29]$ & & & $F$ & \\
\hline & Bolzetta 2021 & 12 & 24 & 29 & 57 & $2.7 \%$ & $0.98[0.61,1.58]$ & & & & \\
\hline & Canoglu 2020 & 10 & 56 & 44 & 98 & $2.1 \%$ & $0.40[0.22,0.73]$ & & & & \\
\hline & Daughety 2020 & 10 & 27 & 24 & 99 & $2.1 \%$ & $1.53[0.84,2.79]$ & & & & \\
\hline & Di Castelnuovo 2021 & 62 & 418 & 114 & 983 & $3.7 \%$ & $1.28[0.96,1.70]$ & & & 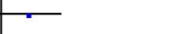 & \\
\hline & Elmelhat 2020 & 3 & 39 & 0 & 20 & $0.2 \%$ & $3.67[0.20,67.85]$ & & & & $\rightarrow$ \\
\hline & Ferguson 2020 & 12 & 46 & 28 & 95 & $2.2 \%$ & $0.89[0.50,1.58]$ & & & - & \\
\hline & Goligher 2021 & 199 & 534 & 200 & 564 & $4.3 \%$ & $1.05[0.90,1.23]$ & & & - & \\
\hline & Hanif 2020 & 86 & 191 & 218 & 672 & $4.2 \%$ & $1.39[1.15,1.68]$ & & & $\rightarrow$ & \\
\hline & Helms 2021 & 11 & 71 & 20 & 108 & $1.8 \%$ & $0.84[0.43,1.64]$ & & & & \\
\hline & Hsu 2020 & 20 & 64 & 56 & 377 & $2.8 \%$ & $2.10[1.36,3.25]$ & & & & \\
\hline & Ionescu 2021 & 307 & 998 & 702 & 2121 & $4.5 \%$ & $0.93[0.83,1.04]$ & & & & \\
\hline & Jean-François 2020 & 2 & 18 & 1 & 8 & $0.3 \%$ & $0.89[0.09,8.44]$ & 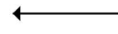 & & & \\
\hline & Jonmarker 2020 & 17 & 85 & 26 & 67 & $2.4 \%$ & $0.52[0.31,0.87]$ & & & & \\
\hline & Kaur 2020 & 109 & 381 & 132 & 652 & $4.0 \%$ & $1.41[1.13,1.76]$ & & & $\rightarrow$ & \\
\hline & Lemos 2020 & 2 & 10 & 5 & 10 & $0.6 \%$ & $0.40[0.10,1.60]$ & & & & \\
\hline & Longhitano 2020 & 10 & 47 & 2 & 27 & $0.6 \%$ & $2.87[0.68,12.15]$ & & & & $\rightarrow$ \\
\hline & Lopes 2021 & 35 & 310 & 23 & 304 & $2.5 \%$ & $1.49[0.90,2.46]$ & & & & \\
\hline & Lynn 2021 & 53 & 152 & 38 & 250 & $3.2 \%$ & $2.29[1.59,3.30]$ & & & & \\
\hline & Marco 2021 & 40 & 149 & 73 & 287 & $3.4 \%$ & $1.06[0.76,1.47]$ & & & E- & \\
\hline & Martinelli 2021 & 12 & 127 & 21 & 151 & $1.9 \%$ & $0.68[0.35,1.33]$ & & & - & \\
\hline & Meizlish 2021 & 19 & 191 & 37 & 191 & $2.5 \%$ & $0.51[0.31,0.86]$ & & & & \\
\hline & Moll 2021 & 12 & 47 & 13 & 47 & $1.8 \%$ & $0.92[0.47,1.81]$ & & & & \\
\hline & Motta 2020 & 29 & 75 & 43 & 299 & $3.1 \%$ & $2.69[1.81,4.00]$ & & & & \\
\hline & Musoke 2020 & 42 & 101 & 33 & 216 & $3.1 \%$ & $2.72[1.84,4.02]$ & & & & \\
\hline & Nadeem 2021 & 23 & 42 & 23 & 34 & $3.3 \%$ & $0.81[0.56,1.16]$ & & & - & \\
\hline & Nadkarni 2020 & 257 & 900 & 424 & 1959 & $4.4 \%$ & $1.32[1.15,1.51]$ & & & - & \\
\hline & Paolisso 2020 & 4 & 89 & 75 & 361 & $1.1 \%$ & $0.22[0.08,0.58]$ & & & & \\
\hline & Paranjpe 2020 & 179 & 786 & 445 & 1987 & $4.4 \%$ & $1.02[0.87,1.18]$ & & & - & \\
\hline & Patrick 2021 & 86 & 1180 & 86 & 1046 & $3.7 \%$ & $0.89[0.67,1.18]$ & & & - & \\
\hline & Perepu 2021 & 13 & 87 & 18 & 86 & $1.9 \%$ & $0.71[0.37,1.37]$ & & & - & \\
\hline & Pesavento 2020 & 14 & 84 & 27 & 240 & $2.1 \%$ & $1.48[0.82,2.69]$ & & & & \\
\hline & Poulakou 2021 & 2 & 54 & 1 & 26 & $0.2 \%$ & $0.96[0.09,10.14]$ & & & & $\rightarrow$ \\
\hline & Qin 2021 & 25 & 77 & 19 & 109 & $2.4 \%$ & $1.86[1.11,3.13]$ & & & - & \\
\hline & Rodolfo 2021 & 12 & 212 & 9 & 109 & $1.4 \%$ & $0.69[0.30,1.58]$ & & & & \\
\hline & Takayama 2021 & 0 & 33 & 5 & 29 & $0.2 \%$ & $0.08[0.00,1.39]$ & & & - & \\
\hline & Vaughn 2021 & 58 & 216 & 211 & 966 & $3.9 \%$ & $1.23[0.96,1.58]$ & & & - & \\
\hline & Voicu 2021 & 20 & 43 & 18 & 50 & $2.6 \%$ & $1.29[0.79,2.11]$ & & & & \\
\hline & Yu 2021 & 80 & 133 & 131 & 215 & $4.3 \%$ & $0.99[0.83,1.18]$ & & & - & \\
\hline & Total $(95 \% \mathrm{Cl})$ & & 8373 & & 15206 & $100.0 \%$ & $1.12[0.99,1.25]$ & & & 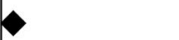 & \\
\hline & Total events & 2014 & & 3497 & & & & & & & \\
\hline & $\begin{array}{l}\text { Heterogeneity: } \operatorname{Tau}^{2}= \\
\text { Test for overall effect: }\end{array}$ & $\begin{array}{l}0.08 ; C h i \\
Z=1.85\end{array}$ & $\begin{array}{l}i^{2}=160 \\
(P=0\end{array}$ & $\begin{array}{l}0.71, \mathrm{df}= \\
06)\end{array}$ & $=38(\mathrm{P}$ & $<0.00001$ & $1) ; I^{2}=76 \%$ & $\begin{array}{ll}0.1 & 0.2\end{array}$ & . & & 10 \\
\hline & & I-TAC & $c$ & PAC & & & Risk Ratio & & Risk R & Ratio & \\
\hline h & Study or Subgroup & Events & Total & Events & Total & Weight $\mathrm{N}$ & $\mathrm{M}-\mathrm{H}$, Random, $95 \% \mathrm{Cl}$ & & $\mathrm{M}-\mathrm{H}$, Rando & om, $95 \% \mathrm{Cl}$ & \\
\hline D & Bikedeli 2021 & 127 & 276 & 123 & 286 & $26.1 \%$ & $1.07[0.89,1.29]$ & & & $=-$ & \\
\hline & Ferguson 2020 & 12 & 46 & 28 & 95 & $6.7 \%$ & $0.89[0.50,1.58]$ & & & & \\
\hline & Goligher 2021 & 199 & 534 & 200 & 564 & $28.8 \%$ & $1.05[0.90,1.23]$ & & & - & \\
\hline & Helms 2021 & 11 & 71 & 20 & 108 & $5.2 \%$ & $0.84[0.43,1.64]$ & & & & \\
\hline & Jean-François 2020 & 2 & 18 & 1 & 8 & $0.5 \%$ & $0.89[0.09,8.44]$ & & & & \\
\hline & Jonmarker 2020 & 17 & 85 & 26 & 67 & $7.9 \%$ & $0.52[0.31,0.87]$ & & & & \\
\hline & Martinelli 2021 & 12 & 127 & 21 & 151 & $5.2 \%$ & $0.68[0.35,1.33]$ & & & - & \\
\hline & Moll 2021 & 12 & 47 & 13 & 47 & $5.2 \%$ & $0.92[0.47,1.81]$ & & & & \\
\hline & Perepu 2021 & 13 & 87 & 18 & 86 & $5.5 \%$ & $0.71[0.37,1.37]$ & & & - & \\
\hline & Takayama 2021 & 0 & 33 & 5 & 29 & $0.3 \%$ & $0.08[0.00,1.39]$ & $\leftarrow$ & & & \\
\hline & Voicu 2021 & 20 & 43 & 18 & 50 & $8.7 \%$ & $1.29[0.79,2.11]$ & & & & \\
\hline & Total $(95 \% \mathrm{Cl})$ & & 1367 & & 1491 & $100.0 \%$ & $0.94[0.79,1.10]$ & & & & \\
\hline & Total events & 425 & & 473 & & & & & & & \\
\hline & $\begin{array}{l}\text { Heterogeneity: } \mathrm{Tau}^{2}= \\
\text { Test for overall effect: }\end{array}$ & $\begin{array}{l}0.02 ; \mathrm{Chi} \\
\mathrm{Z}=0.80\end{array}$ & $\begin{array}{l}i^{2}=14 \\
(P=0 .\end{array}$ & $\begin{array}{l}4.25, \mathrm{df}= \\
.42)\end{array}$ & $=10(P=$ & $=0.16) ; I^{2}$ & $2=30 \%$ & $\begin{array}{ll} & 1 \\
0.1 & 0.2\end{array}$ & $\begin{array}{c}0.5 \\
\text { vours I-TAC }\end{array}$ & $1 \frac{1}{2}$ & $\overrightarrow{10}$ \\
\hline & $\begin{array}{l}\text { Forest plot of the effe } \\
\text {; b Forest plot of the } \\
\text { admitted to ICU }\end{array}$ & $\begin{array}{l}\text { ect of inte } \\
\text { effect of in }\end{array}$ & $\begin{array}{l}\text { ermedic } \\
\text { nterme }\end{array}$ & $\begin{array}{l}\text { late-to-th } \\
\text { ediate-to- }\end{array}$ & $\begin{array}{l}\text { erapeuti } \\
\text { therape }\end{array}$ & $\begin{array}{l}\text { ic versus } p \\
\text { utic versu }\end{array}$ & $\begin{array}{l}\text { prophylactic anticoagulat } \\
\text { us prophylactic anticoagu }\end{array}$ & $\begin{array}{l}\text { ation on in } \\
\text { ulation on }\end{array}$ & $\begin{array}{l}\text { ospital morta } \\
\text {-hospital mo }\end{array}$ & $\begin{array}{l}\text { ality in general } \\
\text { ortality in COVID }\end{array}$ & $\begin{array}{l}\text { COVID -19 } \\
-19\end{array}$ \\
\hline
\end{tabular}


demonstrated that intermediate-to-therapeutic anticoagulation was not significantly associated with reduced inhospital mortality compared to prophylactic anticoagulation in unselected hospitalized COVID-19 patients $(\mathrm{RR}=$ 1.12, $95 \%$ CI $\left.0.99-1.25, \mathrm{p}=0.06, \mathrm{I}^{2}=77 \%\right)$. The sensitivity analysis by leave-one-out approach indicated that the result was relatively stable because the risk ratio remained unchangeable though p value fluctuated around 0.05, as shown in Additional file 6. The funnel plot and Egger test $(\mathrm{p}=0.79)$ showed no evidence of significant publication bias, as shown in Additional file 7. The quality of evidence for in-hospital mortality for general COVID patients was rated as very low using GRADE framework in view of high heterogeneity and potential selection bias (Additional file 8).

Eleven studies $[34,38,39,41,43,55,58,61,64,67$, 70] exclusively investigated in-hospital mortality of critically ill COVID-19 patients admitted to ICU. The subgroup analysis of ICU patients also indicated that intermediate-to-therapeutic anticoagulation was not significantly associated with reduced in-hospital mortality when compared with prophylactic anticoagulation and heterogeneity across the studies decreased significantly ( $R R=0.94,95 \%$ CI 0.79-1.10, $\mathrm{p}=0.42, \mathrm{I}^{2}=30 \%$, see Fig. $2 \mathrm{~b}$ ). The quality of evidence for subgroup analysis of ICU settings regarding in-hospital mortality were rated as moderate-quality, as shown in Additional file 8. In the subgroup analysis stratified by study regions, we also did not observe a significant survival benefit in patients receiving intermediate-to-therapeutic anticoagulation as compared with those receiving prophylactic anticoagulation although the heterogeneity across different subgroups was high (see Additional file 9).

\section{Bleeding events}

A total of 27 studies [34-41, 44, 46-48, 50, 51, 53, 55, $58,59,61,62,64-67,70,71,73$ ] including 19,275 patients assessed the incidence of any bleeding events in intermediate-to-therapeutic anticoagulation group and prophylactic anticoagulation group. COVID-19 patients admitted to general wards, the average incidence of any bleeding events was $2.27 \%$ in prophylactic anticoagulation and $5.50 \%$ in intermediate-to-therapeutic anticoagulation group. In ICU settings, the average bleeding incidence was $7.14 \%$ in prophylactic anticoagulation group and $10.2 \%$ in intermediate-to-therapeutic anticoagulation group. As shown in Fig. 3a, intermediate-totherapeutic anticoagulation was significantly associated an increased incidence of any bleeding events when compared to prophylactic anticoagulation $(\mathrm{RR}=2.16$, $95 \%$ CI $\left.1.79-2.60, \mathrm{p}<0.01, \mathrm{I}^{2}=31 \%\right)$. The predefined sensitivity analyses did not change the overall effect and the results remained stable (Additional file 10). Besides, evidence of publication bias was not found according to the funnel plot and following Egger test $(\mathrm{p}=0.757)$
(Additional file 11). The quality of evidence for bleeding events was rated as moderate using GRADE framework, as shown in Additional file 12. Figure 3b further showed that intermediate-to-therapeutic anticoagulation was also associated with higher incidence of major bleeding events significantly $(R R=2.11,95 \% C I$ 1.77-2.51, $\mathrm{p}<0.01$, $\left.\mathrm{I}^{2}=11 \%\right)$.

Subgroup analysis of bleeding risk related to thromboprophylaxis in ICU settings included 10 studies [34, 38, $39,41,50,55,58,61,64,70]$ and 4596 patients totally, showing that intermediate-to-therapeutic anticoagulation was significantly associated with increased incidence of any bleeding events with low heterogeneity $(R R=1.66$, $95 \%$ CI $1.37-2.00, \mathrm{p}<0.01, \mathrm{I}^{2}=0 \%$, Fig. 3c). The quality of evidence for subgroup analyses of ICU settings regarding bleeding incidence were rated as moderate-quality evidence respectively, as shown in Additional file 12.

\section{Thrombotic complication events}

Incidence of thrombotic events was reported in 17 studies [34-39, 41-43, 47, 56, 58, 60-62, 64, 66] which included a total of 8,492 admitted patients with COVID-19. The results ranged widely across studies with an average incidence of $3.75 \%$ for prophylactic anticoagulation group and $6.45 \%$ for intermediate-totherapeutic anticoagulation group in non-critically ill patients, while $13.0 \%$ for prophylactic group and $8.58 \%$ for intermediate-to-therapeutic anticoagulation group in ICU patients. As shown in Fig. 4a, the current meta-analysis found that the pooled risk ratio of thrombotic events risk did not favor either of two groups with high heterogeneity $(\mathrm{RR}=1.30,95 \% \mathrm{CI}$ $\left.0.79-2.15, \mathrm{p}=0.30, \mathrm{I}^{2}=88 \%\right)$. The predefined sensitivity analysis conformed the stability of the results in this meta-analysis, as shown in Additional file 13. The funnel plot and following Egger test $(p=0.45)$ further indicated no evidence of significant publication bias (Additional file 14). The quality of evidence for thrombotic events was rated as very low using GRADE framework, as shown in Additional file 15.

Subgroup analysis of studies exclusively enrolling critically ill COVID-19 patients admitted to ICU indicated that patients receiving intermediate-to-therapeutic anticoagulation were associated with reduced risk of thrombotic events compared with prophylactic anticoagulation ( $\mathrm{RR}=0.71,95 \% \mathrm{CI} 0.56-0.89, \mathrm{p}=0.03, \mathrm{I}^{2}=0 \%$, as shown in Fig. 4b. The quality of evidence for these subgroup analyses were rated as moderate-quality for ICU settings, as shown in Additional file 15.

\section{Discussion}

In this systemic review and meta-analysis, we included 42 studies with 28,055 COVID-19 patients admitted to hospital in total. By analyzing data of 23,579 hospitalized 


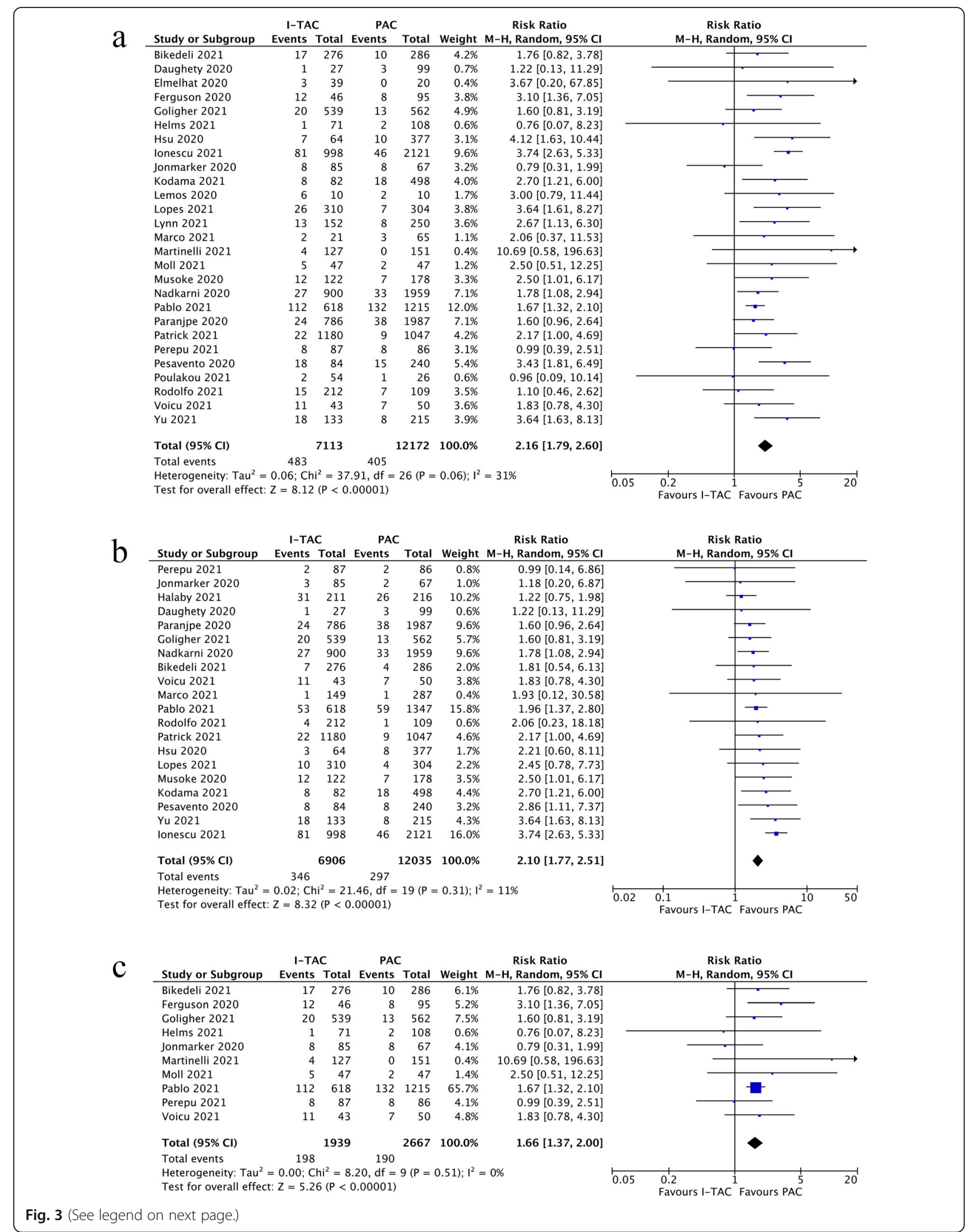


(See figure on previous page.)

Fig. 3 a Forest plot of the effect of intermediate-to-therapeutic versus prophylactic anticoagulation on any bleeding events in general COVID -19 patients; $\mathbf{b}$ Forest plot of the effect of intermediate-to-therapeutic versus prophylactic anticoagulation on major bleeding events in general COVID-19 patients; c Forest plot of the effect of intermediate-to-therapeutic versus prophylactic anticoagulation on any bleeding events in COVID-19 patients admitted to ICU

COVID -19 patients from 33 cohort studies and 6 RCTs reporting in-hospital mortality, intermediate-totherapeutic anticoagulation did not improve the primary outcome of in-hospital mortality in unselected hospitalized COVID-19 patients when compared with prophylactic anticoagulation. Additionally, a subgroup analysis of critically ill COVID-19 patients admitted to ICU also showed no significant survival benefit of intermediateto-therapeutic anticoagulation against standard thromboprophylaxis. These results were inconsistent with earlier studies which reported a significant association between enhanced-dose anticoagulation and improved outcomes $[51,65]$. It is noteworthy that the average inhospital mortality for non-critically ill COVID-19 patients was $22.1 \%$ for prophylactic anticoagulation group and $22.6 \%$ for intermediate-to-therapeutic anticoagulation group in our meta-analysis, suggesting a relatively moderate-to-severe illness in such patients where the underlying thrombotic states and inflammatory damage may have been too advanced to be influenced and improved by higher doses of anticoagulants. In contrast, the latest adaptive, multiplatform, controlled trial (ATTACC, ACTIV-4a and REMAP-CAP) found that therapeutic-dose anticoagulation was associated with

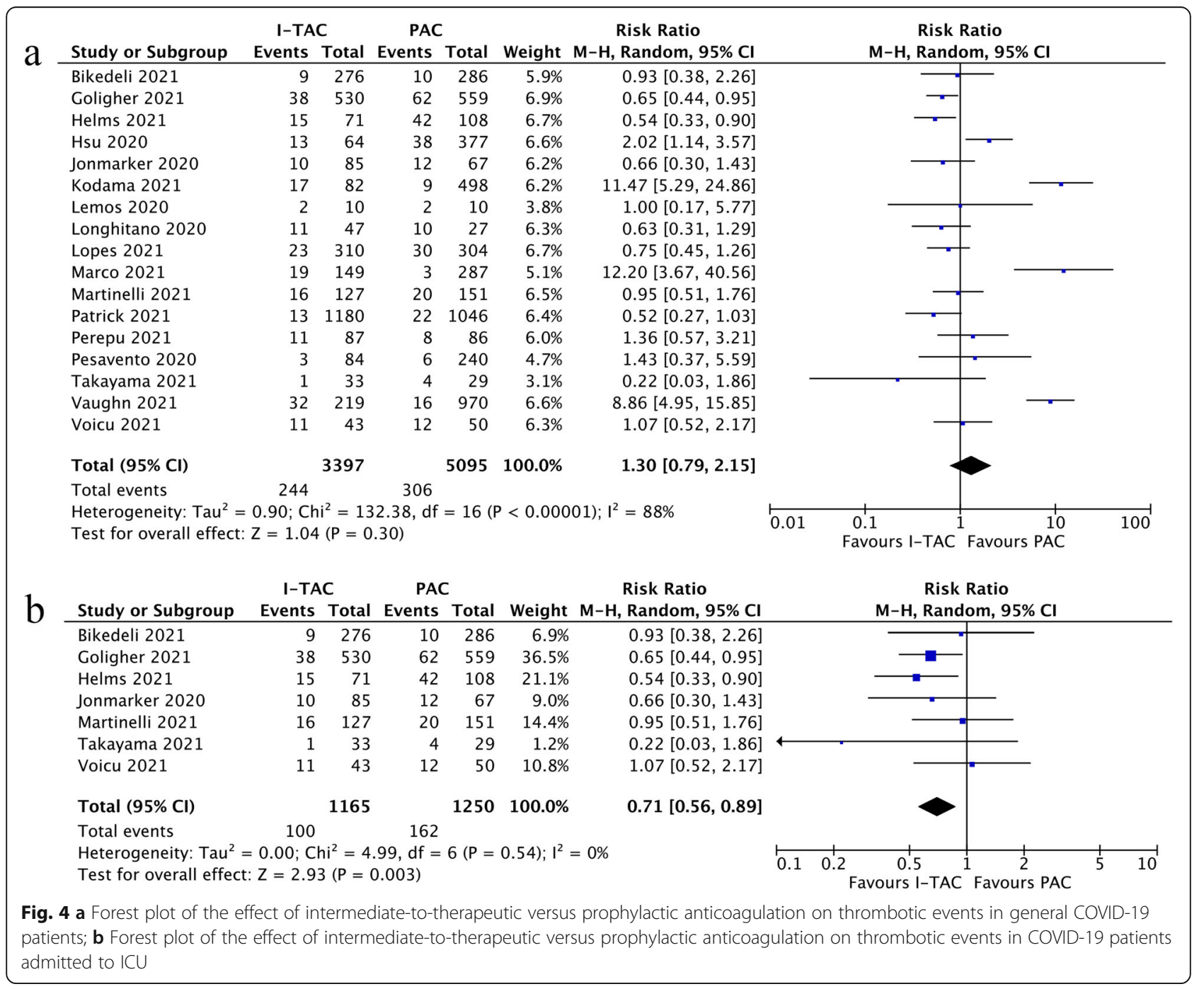


lower mortality until hospital discharge with a reduced need for organ support in the moderately ill COVID-19 patients with a crude 28-day in-hospital mortality of only $8.2 \%$ for prophylactic anticoagulation group and $7.3 \%$ for intermediate-to-therapeutic anticoagulation group [37]. Beyond clinical settings, different study countries might also have different discernible outcomes. As shown in Additional file 9, our subgroup analysis classified by study regions found that intermediate-totherapeutic anticoagulation was not associated with lower in-hospital mortality in the pooled analysis of studies from South America, Europe, East Asia and West Asia. Data from North America even showed a significant survival benefit of prophylactic anticoagulation in unselected hospitalized COVID-19 patients as compared with intermediate-to-therapeutic anticoagulation. In general, the available evidence showed that therapeutic anticoagulation did not reduce in-hospital mortality in both critically ill and non-selected patients with COVID19 , and the evidence was of moderate quality for severe COVID-19 patients admitted to ICU and of very low quality for general COVID-19 patients admitted to hospital. Heterogeneity across the included studies was high, which might derive from different study design, imbalances in baseline characteristics, varied anticoagulation therapy (e.g., drug type, exact dosage, and route), diverse disease severity or different study countries.

Additionally, meta-analysis of data from 11 cohort studies and 6 RCTs reporting thrombotic events indicated that intermediate-to-therapeutic anticoagulation did not reduce relative risk of thrombotic events either versus prophylactic anticoagulation in general COVID19 patients. However, a subgroup analysis of critically ill patients admitted to ICU found intermediate-totherapeutic anticoagulation significantly reduced the incidence of thrombotic events by $30 \%$. These results should be interpreted with caution considering that possible insufficient thrombosis screening in patients admitted to general wards might inevitably influence the reliability of this evidence [76].

Recent studies have also reported high incidences of hemorrhage among inpatients with COVID-19. In this meta-analysis, we observed a significant increase of incidence of any bleeding events and major bleeding events in both general and critically ill patients receiving intermediate-to-therapeutic anticoagulation when compared with prophylactic anticoagulation. Especially, in critically ill COVID-19 patients, use of intermediate-totherapeutic dose anticoagulants significantly reduced incidence of thrombotic events by $30 \%$ but increased incidence of bleeding events by nearly $70 \%$, without a beneficial effect on patient survival. Therefore, the potential profit of elevated dose anticoagulation of thromboprophylaxis on thrombosis prevention are associated with an increase in bleeding events and should thus be weighed against the risk of bleeding.

Growing evidences have arisen to determine the optimal anticoagulation strategy that weighs thrombotic events and consequent bleeding risk in hospitalized patients with COVID-19. In the updated guidelines on the use of anticoagulants for thromboprophylaxis in COVID-19 patients, the American Society of Hematology recommended prophylactic anticoagulation over intermediate anticoagulation in COVID-19 patients with no confirmed or suspected thromboembolism based on low certainty of the evidence [77]. The latest NICE guideline also recommended a standard prophylactic dose of a low molecular weight heparin to young people and adults with COVID-19 who need low-flow or high-flow oxygen, continuous positive airway pressure, non-invasive ventilation or invasive mechanical ventilation within $14 \mathrm{~h}$ of admission [78]. Consistently, our meta-analysis further confirmed the insufficient beneficial effects of high-dose anticoagulation in general COVID-19 patients admitted to hospital. It is also noteworthy that the main outcomes in the included RCTs were typically composite endpoints [35, 37, 38, 79], which were not necessarily all related to the same end goal and limited the potential impact of these results in our daily clinical practice [76]. We instead focused on single endpoints like in-hospital mortality, thrombotic events and bleeding events. Therefore, the fact that therapeutic anticoagulation improved the composite outcome involving survival and receipt of organ support among non-critically ill patients in the multiplatform trials [37] is not as such recognized in the present review.

COVID-19 patients may exhibit complex coagulopathy states. Thrombotic and bleeding events are staggered in time and hypercoagulable states are not always consistent in the course of disease. A recent literature review by Tacquard, et al. demonstrated that thrombotic events occurred primarily in the first ten days after admission while bleeding events occurred most often late [76]. Hardy et al. also found an increase in thrombin generation with a decrease in overall fibrinolytic capacity during the first week of hospitalization, resulting in a strong procoagulant state. After this early stage of the disease, inflammatory markers and D-dimer levels gradually decreased in survivors, probably in relation to a decrease in the intensity of processes leading to microthrombosis [80]. Thromboprophylaxis strategy in hospitalized COVID-19 patients should thus be related to the disease progression and vary according to the severity of illness. D-dimers and fibrin monomers, another fibrin-related biomarker, have been extensively studied in COVID-19, and elevated levels of such biomarkers are associated with increased disease severity and mortality [81-83]. Recently, Godon, et al. showed that D-dimers and fibrin 
monomers were both useful to predict thrombotic events in COVID-19 patients [82]. The optimal cutoff value was determined at $5700 \mu \mathrm{g} / \mathrm{L}$ for fibrin monomers to predict thrombotic events with a sensitivity of $67 \%$ and a specificity of $77 \%$, while the optimal cutoff value for D-dimers was $3300 \mu \mathrm{g} / \mathrm{L}$ with a sensitivity of $75 \%$ and a specificity of $71 \%$ [82]. Besides, these biomarkers are also of great value to adapt thromboprophylaxis protocol for coagulopathy in COVID-19 patients. Tassiopoulos et al. found D-dimer-driven anticoagulation protocol significantly reduced the overall mortality (31\% vs. $57 \%$ ) in intubated COVID-19 patients using a propensity-matched analysis [84]. Julie et al. further established an individualized, targeted-intensity pharmacologic thromboprophylaxis protocol evaluating degree of illness severity, total body weight, and biomarkers (involving D-dimers and thromboelastography max amplitude) in 803 COVID-19 patients admitted to hospital, and found that patients in the targeted-intensity thromboprophylaxis protocol group experienced significantly fewer thrombotic events, fewer major bleeding events, and lower mortality versus patients treated by standard thromboprophylaxis protocol [85]. These results encouraged the clinicians to adopt an individualized and targeted approach to escalated anticoagulation regimens for coagulopathy in COVID-19 patients admitted to both ICU and ward settings in future studies.

Importantly, the choices of different anticoagulation doses mainly follow local institutional protocols and were decided by the physicians in most studies, which resulted in the inconsistent anticoagulation dosage within the same group leading to potential bias [86]. For instance, in the ATTACC, ACTIV-4a and REMAP-CAP trial including critically ill COVID-19 patients, $22.4 \%$ patients among therapeutic-dose group did not receive therapeutic-dose anticoagulation, whereas $51.7 \%$ patients among control group received an intermediate dose, which may blunt the potential benefit of therapeutic-dose anticoagulation [38, 86]. Another challenge of precise anticoagulation in some COVID-19 patients is heparin resistance that occurs with unfractionated heparin only and entails the need of huge unfractionated heparin dosages to reach the therapeutic target [87, 88]. Therefore, monitoring of anticoagulation with anti-Xa activity is warranted to prevent a possible increased bleeding risk when high dosages of heparin are administered [87, 89].

This study has several limitations. Firstly, we included 36 cohort studies and only 6 RCTs. In those cohort studies, selection bias exists. Patients with higher disease severity and risk of thrombotic events were more likely to be treated by intermediate-to-therapeutic anticoagulation, which might lead to undervaluation of potential benefit. Secondly, most patients enrolled in the included studies were over 60 years old and it will be more reasonable to include patients with a wider age scope considering mortality is significantly higher in the elderly inpatients with COVID-19. Thirdly, the criteria for admission to hospital, definition of in-hospital mortality, bleeding and thrombotic events, follow-up periods and exact dosage of two groups might vary from region to region during different stages of the pandemic, affecting risk of both thrombotic and fatal outcomes. Results of the current meta-analysis should therefore be interpreted with caution considering these limitations.

\section{Conclusions}

Among unselected in-hospital patients with COVID-19, the current meta-analysis showed that intermediate-totherapeutic anticoagulation was not associated with lower in-hospital mortality and incidence of thrombotic events, but increased the risk of bleeding events versus prophylactic anticoagulation. In contrast, intermediateto-therapeutic anticoagulation reduced the risk of thrombotic events with increased incidence of bleeding events in critically COVID-19 patients admitted to ICU. We recommended the use of prophylactic anticoagulation against empirical intermediate-to-therapeutic anticoagulation among unselected hospitalized COVID-19 patients based on low certainty in the evidence. For those with severer illness, the benefits to reduce thrombotic events of intermediate-to-therapeutic anticoagulation should also be weighed cautiously by clinicians because of the significantly increased risk of bleeding associated with higher dose of anticoagulant use. Furthermore, the optimal timing of anticoagulation initiation and treatment duration remains unexplored in this field. More well-designed RCTs that effectively stratify included patients by disease severity, timing of anticoagulation initiation, and treatment duration are highly encouraged to provide high-quality evidence regarding the safety and efficacy of higher dose anticoagulation in different clinical settings.

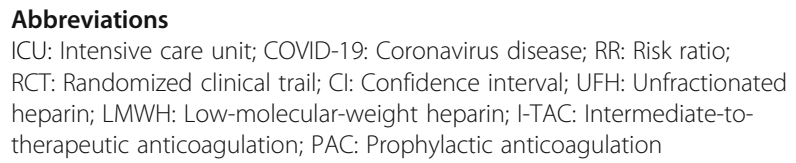

\section{Supplementary Information}

The online version contains supplementary material available at https://doi. org/10.1186/s12959-021-00343-1.

Additional file 1. Detailed search strategy.

Additional file 2. Baseline characteristics of each study.

Additional file 3. Details of anticoagulation administration in each study.

Additional file 4. Quality assessment of cohort studies by NOS score. 
Additional file 5. Quality assessment of RCTs by Cochrane Collaboration tool.

Additional file 6. Sensitivity analysis of in-hospital mortality outcome. Additional file 7. Funnel plot for the assessment risk of publication bias of in-hospital mortality outcome.

Additional file 8. The quality of evidence for in-hospital mortality assessed by GRADE framework.

Additional file 9. Subgroup analysis of in-hospital mortality stratified by study regions.

Additional file 10. Sensitivity analysis of bleeding events outcome.

Additional file 11. Funnel plot for the assessment risk of publication bias of bleeding events outcome.

Additional file 12. The quality of evidence for bleeding events assessed by GRADE framework.

Additional file 13. Sensitivity analysis of thrombotic complication events outcome.

Additional file 14. Funnel plot for the assessment risk of publication bias of thrombotic complication events outcome.

Additional file 15. The quality of evidence for thrombotic complication events assessed by GRADE framework.

\section{Acknowledgements}

Not applicable.

\section{Authors' contributions}

ZSR and LYP searched the relevant literature, collected the data and performed data analyses. LYP and SBH contributed to the design of study and data interpretation. ZSR and LGN wrote the first draft. LYP and SBH critically revised the manuscript. All authors read and approved the manuscript.

\section{Funding}

This work was financially sponsored by the 1.3 .5 project for disciplines of excellence from West China Hospital of Sichuan University (Grant No. ZYJC21010), the National Natural Science Foundation of China (Grant No. 82000702), and Med+ Biomaterial Institute of West China Hospital/ West China School of Medicine of Sichuan University (Grant No. ZYME20001).

\section{Availability of data and materials}

The dataset generated and analyzed during the current study can be found in the included studies and their additional information files.

\section{Declarations}

Ethics approval and consent to participate

Not applicable (systematic review and meta-analysis of published literature).

\section{Consent for publication}

Not applicable.

\section{Competing interests}

The authors declare that they have no competing interests.

\section{Author details}

'West China School of Medicine, Sichuan University, 610041 Chengdu, China. ${ }^{2}$ Department of Nephrology, Med+ Biomaterial Institute, West China Hospital, Sichuan University, 610041 Chengdu, China. Institute for Disaster Management and Reconstruction, Sichuan University, 610207 Chengdu China. ${ }^{4}$ The first People's Hospital of Shuangliu District, 610200 Chengdu, China. ${ }^{5}$ Med-X Center for Materials, Sichuan University, 610041 Chengdu, China.
Received: 30 September 2021 Accepted: 4 November 2021

Published online: 24 November 2021

\section{References}

1. Zhu N, Zhang D, Wang W, Li X, Yang B, Song J, Zhao X, Huang B, Shi W, Lu $\mathrm{R}$, et al. A Novel Coronavirus from Patients with Pneumonia in China, 2019. N Engl J Med. 2020;382(8):727-33.

2. Middeldorp S, Coppens M, van Haaps TF, Foppen M, Vlaar AP, Müller MCA, Bouman CCS, Beenen LFM, Kootte RS, Heijmans J, et al. Incidence of venous thromboembolism in hospitalized patients with COVID-19. J Thromb Haemost. 2020;18(8):1995-2002.

3. Zhang L, Feng X, Zhang D, Jiang C, Mei H, Wang J, Zhang C, Li H, Xia X, Kong $S$, et al. Deep Vein Thrombosis in Hospitalized Patients With COVID-19 in Wuhan, China: Prevalence, Risk Factors, and Outcome. Circulation. 2020; 142(2):114-28

4. Klok FA, Kruip M, van der Meer NJM, Arbous MS, Gommers D, Kant KM, Kaptein FHJ, van Paassen J, Stals MAM, Huisman MV, et al. Confirmation of the high cumulative incidence of thrombotic complications in critically ill ICU patients with COVID-19: An updated analysis. Thromb Res. 2020;191: $148-50$

5. Mirsadraee S, Gorog DA, Mahon CF, Rawal B, Semple TR, Nicol ED, Arachchillage DRJ, Devaraj A, Price S, Desai SR, et al. Prevalence of Thrombotic Complications in ICU-Treated Patients With Coronavirus Disease 2019 Detected With Systematic CT Scanning. Crit Care Med. 2021;49(5):80415.

6. Xiong X, Chi J, Gao Q: Prevalence and risk factors of thrombotic events on patients with COVID-19: a systematic review and meta-analysis. Thromb J. 2021, 19(1):32.

7. Fontelo P, Bastola MM, Zheng Z, Baik SH: A review of thromboembolic events in hospitalized COVID-19 patients. Thromb J. 2021, 19(1):47.

8. Jiménez D, García-Sanchez A, Rali P, Muriel A, Bikdeli B, Ruiz-Artacho P, Le Mao R, Rodríguez C, Hunt BJ, Monreal M: Incidence of VTE and Bleeding Among Hospitalized Patients With Coronavirus Disease 2019: A Systematic Review and Meta-analysis. Chest 2021, 159(3):1182-1196.

9. Varga Z, Flammer AJ, Steiger $P$, Haberecker $M$, Andermatt $R$, Zinkernagel AS, Mehra MR, Schuepbach RA, Ruschitzka F, Moch H: Endothelial cell infection and endotheliitis in COVID-19. Lancet 2020, 395(10234):1417-1418.

10. Nicolai L, Leunig A, Brambs S, Kaiser R, Weinberger T, Weigand M, Muenchhoff M, Hellmuth JC, Ledderose S, Schulz H et al: Immunothrombotic Dysregulation in COVID-19 Pneumonia Is Associated With Respiratory Failure and Coagulopathy. Circulation 2020, 142(12):11761189.

11. Iba T, Levy JH, Levi M, Thachil J: Coagulopathy in COVID-19. J Thromb Haemost 2020, 18(9):2103-2109.

12. Rochwerg B, Agarwal A, Siemieniuk RA, Agoritsas T, Lamontagne F, Askie L, Lytvyn L, Leo YS, Macdonald H, Zeng L et al: A living WHO guideline on drugs for covid-19. BMJ (Clinical research ed) 2020,370:m3379.

13. Cuker A, Tseng EK, Nieuwlaat R, Angchaisuksiri P, Blair C, Dane K, Davila J, DeSancho MT, Diuguid D, Griffin DO et al: American Society of Hematology 2021 guidelines on the use of anticoagulation for thromboprophylaxis in patients with COVID-19. Blood adv 2021, 5(3):872-888.

14. Gerotziafas GT, Catalano M, Colgan MP, Pecsvarady Z, Wautrecht JC, Fazeli B, Olinic DM, Farkas K, Elalamy I, Falanga A et al: Guidance for the Management of Patients with Vascular Disease or Cardiovascular Risk Factors and COVID-19: Position Paper from VAS-European Independent Foundation in Angiology/Nascular Medicine. Thromb Haemost 2020, 120(12):1597-1628.

15. Kyriakoulis KG, Kollias A, Kyriakoulis IG, Kyprianou IA, Papachrysostomou C, Makaronis P, Kotronias RA, Terentes-Printzios D, Toskas I, Mikhailidis DP: Thromboprophylaxis in Patients with COVID-19: Systematic Review of National and International Clinical Guidance Reports. Curr Vasc Pharmacol 2021

16. Klok FA, Kruip M, van der Meer NJM, Arbous MS, Gommers D, Kant KM, Kaptein FHJ, van Paassen J, Stals MAM, Huisman MV et al: Incidence of thrombotic complications in critically ill ICU patients with COVID-19. Thromb Res 2020, 191:145-147.

17. Helms J, Tacquard C, Severac F, Leonard-Lorant I, Ohana M, Delabranche X, Merdji H, Clere-Jehl R, Schenck M, Fagot Gandet F et al: High risk of thrombosis in patients with severe SARS-CoV-2 infection: a multicenter prospective cohort study. Intensive Care Med 2020, 46(6):1089-1098. 
18. Santoro F, Núñez-Gil IJ, Viana-Llamas MC, Maroun Eid C, Romero R, Fernández Rozas I, Aparisi A, Becerra-Muñoz VM, García Aguado M, Huang J et al: Anticoagulation Therapy in Patients With Coronavirus Disease 2019: Results From a Multicenter International Prospective Registry (Health Outcome Predictive Evaluation for Corona Virus Disease 2019 [HOPECOVID19]). Crit Care Med 2021, 49(6):e624-e633.

19. Rosovsky RP, Sanfilippo KM, Wang TF, Rajan SK, Shah S, Martin KA, F NÁ, Huisman M, Hunt BJ, Kahn SR et al: Anticoagulation Practice Patterns in COVID-19: A Global Survey. Res Pract Thromb Haemost 2020, 4(6):969-983.

20. Susen S, Tacquard CA, Godon A, Mansour A, Garrigue D, Nguyen P, Godier A, Testa S, Levy JH, Albaladejo P et al: Prevention of thrombotic risk in hospitalized patients with COVID-19 and hemostasis monitoring. Crit care (Lond, Engl) 2020, 24(1):364.

21. Lavinio A, Ercole A, Battaglini D, Magnoni S, Badenes R, Taccone FS, Helbok R, Thomas W, Pelosi P, Robba C: Safety profile of enhanced thromboprophylaxis strategies for critically ill COVID-19 patients during the first wave of the pandemic: observational report from 28 European intensive care units. Crit care (Lond, Engl) 2021, 25(1):155.

22. Flaczyk A, Rosovsky RP, Reed CT, Bankhead-Kendall BK, Bittner EA, Chang MG: Comparison of published guidelines for management of coagulopathy and thrombosis in critically ill patients with COVID 19: implications for clinical practice and future investigations. Crit care (Lond, Engl) 2020, 24(1):559.

23. Patell R, Chiasakul T, Bauer E, Zwicker Jl: Pharmacologic Thromboprophylaxis and Thrombosis in Hospitalized Patients with COVID-19: A Pooled Analysis. Thromb Haemost 2021, 121(1):76-85.

24. Abdel-Maboud M, Menshawy A, Elgebaly A, Bahbah El, El Ashal G, Negida A: Should we consider heparin prophylaxis in COVID-19 patients? a systematic review and meta-analysis. J Thromb Thrombolysis 2020.

25. Wijaya I, Andhika R, Huang I: The Use of Therapeutic-Dose Anticoagulation and Its Effect on Mortality in Patients With COVID-19: A Systematic Review. Clin Appl Thromb Hemost 2020, 26.

26. Liberati A, Altman DG, Tetzlaff J, Mulrow C, Gøtzsche PC, loannidis JP, Clarke M, Devereaux PJ, Kleijnen J, Moher D: The PRISMA statement for reporting systematic reviews and meta-analyses of studies that evaluate healthcare interventions: explanation and elaboration. BMJ (Clinical research ed) 2009, 339:b2700.

27. Higgins JP, Altman DG, Gøtzsche PC, Jüni P, Moher D, Oxman AD, Savovic J, Schulz KF, Weeks L, Sterne JA: The Cochrane Collaboration's tool for assessing risk of bias in randomised trials. BMJ (Clinical research ed) 2011, 343:d5928.

28. Stang A: Critical evaluation of the Newcastle-Ottawa scale for the assessment of the quality of nonrandomized studies in meta-analyses. Eur J Epidemiol 2010, 25(9):603-605.

29. Guyatt $G H$, Oxman AD, Vist GE, Kunz R, Falck-Ytter Y, Alonso-Coello P, Schünemann HJ: GRADE: an emerging consensus on rating quality of evidence and strength of recommendations. BMJ (Clinical research ed) 2008, 336(7650):924-926

30. Mehran R, Rao SV, Bhatt DL, Gibson CM, Caixeta A, Eikelboom J, Kaul S, Wiviott SD, Menon V, Nikolsky E et al: Standardized bleeding definitions for cardiovascular clinical trials: a consensus report from the Bleeding Academic Research Consortium. Circulation 2011, 123(23):2736-2747.

31. Fogarty PF, Tarantino MD, Brainsky A, Signorovitch J, Grotzinger KM: Selective validation of the WHO Bleeding Scale in patients with chronic immune thrombocytopenia. Curr Med Res Opin 2012, 28(1):79-87.

32. Slichter SJ, Kaufman RM, Assmann SF, McCullough J, Triulzi DJ, Strauss RG, Gernsheimer TB, Ness PM, Brecher ME, Josephson CD et al: Dose of prophylactic platelet transfusions and prevention of hemorrhage. N Engl J Med 2010, 362(7):600-613

33. Schulman S, Angerås U, Bergqvist D, Eriksson B, Lassen MR, Fisher W: Definition of major bleeding in clinical investigations of antihemostatic medicinal products in surgical patients. J Thromb Haemost 2010, 8(1):202-204.

34. Perepu US, Chambers I, Wahab A, Ten Eyck P, Wu C, Dayal S, Sutamtewagul G, Bailey SR, Rosenstein LJ, Lentz SR: Standard prophylactic versus intermediate dose enoxaparin in adults with severe COVID-19: A multicenter, open-label, randomized controlled trial. J Thromb Haemost 2021.

35. Lopes RD, de Barros ESPGM, Furtado RHM, Macedo AVS, Bronhara B, Damiani LP, Barbosa LM, de Aveiro Morata J, Ramacciotti E, de Aquino Martins $P$ et al: Therapeutic versus prophylactic anticoagulation for patients admitted to hospital with COVID-19 and elevated D-dimer concentration (ACTION): an open-label, multicentre, randomised, controlled trial. Lancet 2021, 397(10291):2253-2263.

36. Lemos ACB, do Espírito Santo DA, Salvetti MC, Gilio RN, Agra LB, Pazin-Filho A, Miranda $\mathrm{CH}$ : Therapeutic versus prophylactic anticoagulation for severe
COVID-19: A randomized phase II clinical trial (HESACOVID). Thromb Res 2020, 196:359-366.

37. Lawler PR, Goligher EC, Berger JS, Neal MD, McVerry BJ, Nicolau JC, Gong MN, Carrier M, Rosenson RS, Reynolds HR et al: Therapeutic Anticoagulation with Heparin in Noncritically III Patients with Covid-19. N Engl J Med 2021.

38. Goligher EC, Bradbury CA, McVerry BJ, Lawler PR, Berger JS, Gong MN, Carrier M, Reynolds HR, Kumar A, Turgeon AF et al: Therapeutic Anticoagulation with Heparin in Critically III Patients with Covid-19. N Engl J Med 2021.

39. Bikdeli B, Talasaz AH, Rashidi F, Bakhshandeh H, Rafiee F, Rezaeifar P, Baghizadeh E, Matin S, Jamalkhani S, Tahamtan O et al: Intermediate-Dose versus Standard-Dose Prophylactic Anticoagulation in Patients with COVID19 Admitted to the Intensive Care Unit: 90-Day Results from the INSPIRATION Randomized Trial. Thromb Haemost 2021.

40. Yu B, Gutierrez VP, Carlos A, Hoge G, Pillai A, Kelly JD, Menon V: Empiric use of anticoagulation in hospitalized patients with COVID-19: a propensity score-matched study of risks and benefits. Biomark Res 2021, 9(1):29.

41. Voicu S, Chousterman BG, Bonnin P, Deye N, Malissin I, Gall AL, Barthélémy R, Sutterlin L, Naim G, Mrad A et al: Increased anticoagulation reduces proximal deep vein thrombosis in mechanically ventilated COVID-19 patients: Venous thrombosis prevention \& COVID-19. J Infect 2021, 82(5):186-230.

42. Vaughn VM, Yost M, Abshire $C$, Flanders SA, Paje D, Grant P, Kaatz S, Kim T, Barnes GD: Trends in Venous Thromboembolism Anticoagulation in Patients Hospitalized With COVID-19. JAMA netw open 2021, 4(6):e2111788.

43. Takayama W, Endo A, Otomo Y: Anticoagulation therapy using unfractionated heparin at a therapeutic dose for coronavirus disease 2019 patients with severe pneumonia: a retrospective historical control study. Acute Med Surg 2021, 8(1):e679.

44. Rodolfo., Aguilar-Soto M, Rodríguez-Toledo CA, Camiro-Zúñiga A, Demichelis $\mathrm{R}$ : The impact of different prophylactic anticoagulation doses on the outcomes of patients with COVID-19. Thromb Res 2021, 202:14-16.

45. Qin W, Dong F, Zhang Z, Hu B, Chen S, Zhu Z, Li F, Wang X, Zhang Y, Wang $Y$ et al: Low molecular weight heparin and 28-day mortality among patients with coronavirus disease 2019: A cohort study in the early epidemic era. Thromb Res 2021, 198:19-22.

46. Poulakou G, Dimakakos E, Kollias A, Kyriakoulis KG, Rapti V, Trontzas I, Thanos C, Abdelrasoul M, Vantana T, Leontis K et al: Beneficial Effects of Intermediate Dosage of Anticoagulation Treatment on the Prognosis of Hospitalized COVID-19 Patients: The ETHRA Study. In vivo (Athens, Greece) 2021, 35(1):653-661.

47. Pesavento R, Ceccato D, Pasquetto G, Monticelli J, Leone L, Frigo A, Gorgi D, Postal A, Marchese GM, Cipriani A et al: The hazard of (sub)therapeutic doses of anticoagulants in non-critically ill patients with Covid-19: The Padua province experience. J Thromb Haemost 2020, 18(10):2629-2635.

48. Paranjpe I, Fuster V, Lala A, Russak AJ, Glicksberg BS, Levin MA, Charney AW, Narula J, Fayad ZA, Bagiella E et al: Association of Treatment Dose Anticoagulation With In-Hospital Survival Among Hospitalized Patients With COVID-19. J Am Coll Cardiol 2020, 76(1):122-124.

49. Paolisso P, Bergamaschi L, D’Angelo EC, Donati F, Giannella M, Tedeschi S, Pascale R, Bartoletti M, Tesini G, Biffi M et al: Preliminary Experience With Low Molecular Weight Heparin Strategy in COVID-19 Patients. Front Pharmacol 2020, 11:1124.

50. Pablo P, Farfán-Sedano Al, Pedrajas JM, Llamas $P$, Sigüenza $P$, Jaras MJ, Quintana-Diaz M, Fernández-Capitán C, Bikdeli B, Jiménez D et al: Bleeding risk in hospitalized patients with COVID-19 receiving intermediate- or therapeutic doses of thromboprophylaxis. J Thromb Haemost 2021.

51. Nadkarni GN, Lala A, Bagiella E, Chang HL, Moreno PR, Pujadas E, Arvind V, Bose S, Charney AW, Chen MD et al: Anticoagulation, Bleeding, Mortality, and Pathology in Hospitalized Patients With COVID-19. J Am Coll Cardiol 2020, 76(16):1815-1826.

52. Nadeem R, Thomas SJ, Fathima Z, Palathinkal AS, Alkilani YE, Dejan EA, Darwish IMI, Alsubousi AA, Backour AM, Kandeel $\mathrm{H}$ et al: Pattern of anticoagulation prescription for patients with Covid-19 acute respiratory distress syndrome admitted to ICU. Does it impact outcome? Heart Lung 2021, 50(1):1-5.

53. Musoke N, Lo KB, Albano J, Peterson E, Bhargav R, Gul F, DeJoy R, 3rd, Salacup G, Pelayo J, Tipparaju P et al: Anticoagulation and bleeding risk in patients with COVID-19. Thromb Res 2020, 196:227-230.

54. Motta JK, Ogunnaike RO, Shah R, Stroever S, Cedeño HV, Thapa SK, Chronakos JJ, Jimenez EJ, Petrini J, Hegde A: Clinical Outcomes With the Use of Prophylactic Versus Therapeutic Anticoagulation in Coronavirus Disease 2019. Crit Care Explor 2020, 2(12):e0309. 
55. Moll M, Zon RL, Sylvester KW, Rimsans J, Chen EC, Ghosh AJ, Abston E, Kim A, Rutherford H, Mitre X et al: Intermediate versus standard dose heparin prophylaxis in COVID-19 ICU patients: A propensity score-matched analysis. Thromb Res 2021, 203:57-60.

56. Mennuni MG, Renda G, Grisafi L, Rognoni A, Colombo C, Lio V, Foglietta M, Petrilli I, Pirisi M, Spinoni E et al: Clinical outcome with different doses of low-molecular-weight heparin in patients hospitalized for COVID-19. J Thromb Thrombolysis 2021:1-9.

57. Meizlish ML, Goshua G, Liu Y, Fine R, Amin K, Chang E, DeFilippo N, Keating C, Liu Y, Mankbadi M et al: Intermediate-dose anticoagulation, aspirin, and in-hospital mortality in COVID-19: A propensity score-matched analysis. Am J Hematol 2021, 96(4):471-479.

58. Martinelli I, Ciavarella A, Abbattista M, Aliberti S, De Zan V, Folli C, Panigada M, Gori A, Artoni A, lerardi AM et al: Increasing dosages of low-molecularweight heparin in hospitalized patients with Covid-19. Intern Emerg Med 2021, 16(5):1223-1229.

59. Lynn L, Reyes JA, Hawkins K, Panda A, Linville L, Aldhahri W, Kango G, Shah S, Ayanian S, Teufel K: The effect of anticoagulation on clinical outcomes in novel Coronavirus (COVD-19) pneumonia in a U.S. cohort. Thromb Res 2021, 197:65-68.

60. Longhitano Y, Racca F, Zanza C, Muncinelli M, Guagliano A, Peretti E, Minerba AC, Mari M, Boverio R, Salio M et al: Venous Thrombo-Embolism in Hospitalized SARS-CoV-2 Patients Treated with Three Different Anticoagulation Protocols: Prospective Observational Study. Biology 2020, 9(10).

61. Llitjos JF, Leclerc M, Chochois C, Monsallier JM, Ramakers M, Auvray M, Merouani K: High incidence of venous thromboembolic events in anticoagulated severe COVID-19 patients. J Thromb Haemost 2020, 18(7):1743-1746.

62. Kodama R, Kalsi A, Singh A, Vishnuvardhan N, Nimkar N, Paul S, Usta S, Ashraf F, Mazloom A, Ashfaq A et al: Outcomes in COVID-19 patients on treatment dose anti- coagulation compared to prophylactic dose anticoagulation. Blood 2020, 136(SUPPL 1):40-41.

63. Kaur J, Sule AA, Koehler T, Krishnamoorthy G, DeLongpre J: Anticoagulation management and outcomes in COVID-19 patients: A multi-center retrospective cohort study. Blood 2020, 136(SUPPL 1):34.

64. Jonmarker S, Hollenberg J, Dahlberg M, Stackelberg O, Litorell J, Everhov A $H$, Järnbert-Pettersson $H$, Söderberg M, Grip J, Schandl A et al: Dosing of thromboprophylaxis and mortality in critically ill COVID-19 patients. Crit care (Lond, Engl) 2020, 24(1):653.

65. Ionescu F, Jaiyesimi I, Petrescu I, Lawler PR, Castillo E, Munoz-Maldonado Y, Imam Z, Narasimhan M, Abbas AE, Konde A et al: Association of anticoagulation dose and survival in hospitalized COVID-19 patients: A retrospective propensity score-weighted analysis. Eur J Haematol 2021, 106(2):165-174.

66. Hsu A, Liu Y, Zayac AS, Olszewski AJ, Reagan JL: Intensity of anticoagulation and survival in patients hospitalized with COVID-19 pneumonia. Thromb Res 2020, 196:375-378

67. Helms J, Severac F, Merdji H, Schenck M, Clere-Jehl R, Baldacini M, Ohana M, Grunebaum L, Castelain V, Anglés-Cano E et al: Higher anticoagulation targets and risk of thrombotic events in severe COVID-19 patients: bi-center cohort study. Ann Intensive Care 2021, 11(1):14.

68. Hanif A, Khan S, Mantri N, Hanif S, Saleh M, Alla Y, Chinta S, Shrestha N, Ji W, Attwood $\mathrm{K}$ et al: Thrombotic complications and anticoagulation in COVID-19 pneumonia: a New York City hospital experience. Ann Hematol 2020, 99(10):23232328.

69. Halaby R, Cuker A, Yui J, Matthews A, Ishaaya E, Traxler E, Domenico C, Cooper T, Tierney A, Niami P et al: Bleeding risk by intensity of anticoagulation in critically ill patients with COVID-19: A retrospective cohort study. J Thromb Haemost 2021, 19(6):1533-1545.

70. Ferguson J, Volk S, Vondracek T, Flanigan J, Chernaik A: Empiric Therapeutic Anticoagulation and Mortality in Critically III Patients With Respiratory Failure From SARS-CoV-2: A Retrospective Cohort Study. J Clin Pharmacol 2020, 60(11): 1411-1415.

71. Elmelhat A, Elbourai E, Dewedar $\mathrm{H}$, Elgergawi T, Alkhanbouli M, Ahmed S, Malik Z, Nugud A, Mohammed S, Mohammad H et al: Comparison between Prophylactic versus Therapeutic Doses of Low-Molecular-Weight Heparin in Severely III Coronavirus Disease 2019 Patients in Relation to Disease Progression and Outcome. Dubai Med J 2020, 3(4):162-169.

72. Di Castelnuovo A, Costanzo S, Antinori A, Berselli N, Blandi L, Bonaccio M, Cauda R, Guaraldi G, Menicanti L, Mennuni M et al: Heparin in COVID-19 Patients Is Associated with Reduced In-Hospital Mortality: the Multicenter Italian CORIST Study. Thromb Haemost 2021
73. Daughety MM, Morgan A, Frost E, Kao C, Hwang J, Tobin R, Patel B, Fuller M, Welsby I, Ortel TL: COVID-19 associated coagulopathy: Thrombosis, hemorrhage and mortality rates with an escalated-dose thromboprophylaxis strategy. Thromb Res 2020, 196:483-485.

74. Canoglu K, Saylan B: Therapeutic dosing of low-molecular-weight heparin may decrease mortality in patients with severe COVID-19 infection. Ann Saudi Med 2020, 40(6):462-468.

75. Bolzetta F, Maselli M, Formilan M, Busonera F, Albanese P, Chiaromanni F, Romano A, Veronese N: Prophylactic or therapeutic doses of heparins for COVID-19 infection? A retrospective study. Aging Clin Exp Res 2021, 33(1): 213-217.

76. Tacquard C, Mansour A, Godon A, Gruel Y, Susen S, Godier A, Albaladejo P: Anticoagulation in COVID-19: not strong for too long? Anaest Crit Care Pain Med 2021, 40(2):100857.

77. Cuker A, Tseng EK, Nieuwlaat R, Angchaisuksiri P, Blair C, Dane K, Davila J, DeSancho MT, Diuguid DL, Griffin DO et al: American Society of Hematology living guidelines on the use of anticoagulation for thromboprophylaxis in patients with COVID-19: May 2021 update on the use of intermediate intensity anticoagulation in critically ill patients. Blood adv 2021, 5 (20): 3951-3959.

78. National Institute for Health and Care Excellence. COVID-19 rapid guideline: Managing COVID-19. https://www.nice.org.uk/guidance/NG191. Accessed 02 November 2021

79. Sadeghipour P, Talasaz AH, Rashidi F, Sharif-Kashani B, Beigmohammadi MT, Farrokhpour M, Sezavar SH, Payandemehr P, Dabbagh A, Moghadam KG et al: Effect of Intermediate-Dose vs Standard-Dose Prophylactic Anticoagulation on Thrombotic Events, Extracorporeal Membrane Oxygenation Treatment, or Mortality Among Patients With COVID-19 Admitted to the Intensive Care Unit: The INSPIRATION Randomized Clinical Trial. JAMA 2021, 325(16):1620-1630.

80. Hardy M, Michaux I, Lessire S, Douxfils J, Dogné JM, Bareille M, Horlait G, Bulpa P, Chapelle C, Laporte S et al: Prothrombotic disturbances of hemostasis of patients with severe COVID-19: A prospective longitudinal observational study. Thromb Res 2021, 197:20-23.

81. Liao DY, Zhou F, Luo LL, Xu M, Wang HB, Xia JH, Gao Y, Cai LQ, Wang ZH, Yin $P$ et al: Haematological characteristics and risk factors in the classification and prognosis evaluation of COVID-19: a retrospective cohort study. Lancet Haematol 2020, 7(9):E671-E678.

82. Godon A, Durand Z, Agier L, Lecompte T, Mullier F, Marlu R, de Maistre E, Tacquard C, Levy JH, Godier A et al: Comparison of Fibrin Monomers and D-dimers to predict thrombotic events in critically ill patients with COVID-19 pneumonia: A retrospective study. Thromb Res 2021, 205:8-10.

83. Moosavi M, Wooten M, Goodman A, Nahab FB, Duncan A, Maier C, Guarner J: Retrospective Analyses Associate Hemostasis Activation Biomarkers With Poor Outcomes in Patients With COVID-19. Am J Clin Pathol 2021, 155(4): 498-505.

84. Tassiopoulos AK, Mofakham S, Rubano JA, Labropoulos N, Bannazadeh M, Drakos P, Volteas P, Cleri NA, Alkadaa LN, Asencio AA et al: D-Dimer-Driven Anticoagulation Reduces Mortality in Intubated COVID-19 Patients: A Cohort Study With a Propensity-Matched Analysis. Front Med 2021, 8:10.

85. Farrar JE, Trujillo TC, Mueller SW, Beltran L, Nguyen C, Hassell K, Kiser TH: Evaluation of a patient specific, targeted-intensity pharmacologic thromboprophylaxis protocol in hospitalized patients with COVID-19. J Thromb Thrombolysis 2021

86. Ten Cate H: Surviving Covid-19 with Heparin? N Engl J Med 2021, 385(9): 845-846.

87. Novelli C, Borotto E, Beverina I, Punzi V, Radrizzani D, Brando B: Heparin dosage, level, and resistance in SARS-CoV2 infected patients in intensive care unit. Int J Lab Hematol 2021.

88. White D, MacDonald S, Bull T, Hayman M, de Monteverde-Robb R, Sapsford D, Lavinio A, Varley J, Johnston A, Besser M et al: Heparin resistance in COVID-19 patients in the intensive care unit. J Thromb Thrombolysis 2020, 50(2):287-291.

89. Beun R, Kusadasi N, Sikma M, Westerink J, Huisman A: Thromboembolic events and apparent heparin resistance in patients infected with SARS-CoV-2. Int J Lab Hematol 2020, 42:19-20.

\section{Publisher's Note}

Springer Nature remains neutral with regard to jurisdictional claims in published maps and institutional affiliations. 